\title{
O TERRITÓRIO DO SUJEITO IMPLICADO - CIÊNCIA NÔMADE
}

\author{
Maria da Conceição de Almeida ${ }^{1}$
}

\begin{abstract}
Resumo
O artigo problematiza um dos princípios seminais das ciências da complexidade: $a$ reintrodução do sujeito no conhecimento, conforme proposição de Edgar Morin. Tal atitude epistemológica já havia sido expressa por cientistas e pensadores como Michel Eyquem Montaigne, Erwin Schrödinger, Werner Heisenberg e Ilya Prigogine, dentre outros. Como desdobramento dessa problematização, propugna-se uma ciência nômade capaz de facilitar a ampliação e recriação de conceitos e interpretações. Para isso defende-se uma experimentação mais visceral da diversidade dos cenários e contextos imaginários vividos pelo intelectual, o que supõe ousadia, incerteza e coragem para viver sempre novos limites e desafios. Trata-se de afirmar uma ciência da inteireza comprometida com a metamorfose permanente do sujeito e de sua ação no mundo.
\end{abstract}

Palavras-chave: Templo Clássico; Peristilo; Templo Cristão; Realidade e Não-Realidade.

\begin{abstract}
The paper discusses one of the seminal principles of the sciences of complexity: 'reintroduction of subject in knowledge', as Edgar Morin proposition. Such epistemological attitude had been expressed by scientists and thinkers such as Michel Eyquem Montaigne, Erwin Schrödinger, Werner Heisenberg and Ilya Prigogine, among others. As an extension of this questioning, a nomad science able to facilitate the expansion and re-creation of concepts and interpretations is advocated. So it is argued that a more visceral trial of the diversity of scenarios and imaginary contexts experienced by the intellectual, which means boldness, uncertainty and courage to live always new limits and challenges. It is a science of state wholeness committed with the permanent metamorphosis of the subject and its action in the world.
\end{abstract}

Keywords: Classical Temple; Peristyle; Christian Temple; Reality and Non-Reality.

\footnotetext{
${ }^{1}$ Antropóloga. Professora Titular do Departamento de Fundamentos e Políticas da Educação do Centro de Educação da Universidade Federal do Rio Grande do Norte - Brasil. Doutora em Ciências Sociais pela Pontifícia Universidade Católica de São Paulo-SP, Brasil. Professora dos Programas de Pós-Graduação em Educação e em Ciências Sociais da Universidade Federal do Rio Grande do Norte. Coordenadora do Grupo de Estudos da Complexidade - GRECOM
} 
É evidente, mas muito frequentemente esquecido, que a ciência é feita por homens. Werner Heisenberg

Não sou daqueles que têm uma profissão, sou daqueles que têm uma vida - que inclui uma profissão. Edgar Morin

Uma ciência sem sujeito é o mesmo que um livro sem autor, uma casa sem alicerce, um crepúsculo sem sol, um discípulo sem mestre, um corpo sem alma. Uma matemática sem sujeito é o mesmo que um triângulo sem vértices, uma área sem extensão, uma fórmula sem símbolos. Um poeta sem alma equivale a um poema sem palavras. Um educador sem sonhos, dor, desejos, obstáculos e afetos é o mesmo que uma escultura em mármore frio fixada na solidão de um deserto. Um professor que não reconhece na experiência vivida os vetores de sua vontade de compartilhar conhecimentos é um ventríloquo, um personagem sem história. Uma ciência sem subjetividade só faz sentido no interior de um paradigma da racionalização patológica que, diga-se com todas as letras, está longe de enobrecer o uso da razão - esse atributo do pensamento humano sempre aberto às circunstâncias vividas, individual e coletivamente, por homens e mulheres de carne e osso. Um texto excessivamente axiomático e técnico equivale a uma linguagem em código secreto decifrável apenas pelos iniciados de uma seita secreta

O horizonte deste artigo é outro. Repõem os alimentos do afeto, a insubordinação ao estabelecido, as dores e as alegrias que, juntos, compõem as cores de uma ciência com sujeito. Uma ciência da inteireza, uma humana ciência e um intelectual inteiro expõem, por meio das palavras, o coração, "víscera mais nobre porque leva consigo a imagem de um espaço, de um dentro obscuro secreto e misterioso que, em algumas ocasiões, se abre". (ZAMBRANO: 2000, p.23)

Um contexto mais alargado permite compreender a importância da relação entre a história pessoal do cientista e a sua produção de conhecimento. Vamos por parte....

Comecemos por afirmar que, mesmo que as ciências modernas, nascidas no século 17, tenham consagrado o mito da neutralidade, noção que diz respeito a um conhecimento desencarnado, tudo o que é descrito é fruto da experiência de um sujeito imerso numa dada realidade, num determinado tempo. É sempre da sua experiência que falam o autor, o escritor, o cientista. Longe de caracterizar um fenômeno de hoje, pensadores marcados pela consciência da indissociação entre vida e escritura expressaram, com vigor, a relação do sujeito com o fenômeno do qual tratam. "A palavra é metade daquele que a diz, e a metade de 
quem a escuta", dirá Michel de Montaigne nos Ensaios. O astrofísico Hubert Reeves acentua que todas as considerações, argumentos e respostas dos cientistas às questões que lhes são colocadas "só podem ser pessoais".

O russo-belga Ilya Prigogine, Nobel de Química de 1977, argumenta em favor da consciência da subjetivação na ciência. Daí porque, distante da esquizofrenia que por vezes caracteriza o perfil dos cientistas e acadêmicos, Prigogine fala de si, dos percursos e mudanças na sua formação, das dúvidas pessoais que se consubstanciaram posteriormente em mudanças conceituais, dos contextos políticos vividos por ele. Para ele, a indissociação da tríade ciência-razão-paixão é a base do processo criativo na ciência. É também a chave para compreender porque cientistas que compartilham de um mesmo tempo da história da cultura científica se opõem entre si diante de uma mesma teoria nova ou um conceito emergente. Esse é o caso, por exemplo, da aceitação ou negação da teoria da irreversibilidade do tempo. Em Ciência, razão e paixão (2009), Prigogine (2009, p. 45) narra, tendo como referência nomes importantes, o 'papel desempenhado pela paixão no conhecimento e, em termos mais gerais, por elementos 'irracionais'. Discute o papel dos condicionamentos emocionais que oferecem consistência e suporte às concepções determinísticas. Penso que, a esse respeito, Prigogine oferece demonstração e argumentos importantes para todos que sonham e propugnam pela mudança política e também pessoal que, no caso dos construtores da ciência se inicia sempre no domínio mais interior e intimo do pensamento.

Pelo que me é dado a inferir (talvez mesmo por meu modo de ver e viver as circunstâncias que me foram dadas pela vida), há uma distinção importante entre condicionamentos e obstáculos; e, também, um limite tênue entre os dois termos/processos. Os condicionamentos seriam as circunstâncias não escolhidas por nós: nacionalidade, história política, estrutura familiar, acontecimentos que marcam a infância, adolescência e idade adulta; repetições, acasos, incidentes não esperados. Os obstáculos seriam as circunstâncias transformadas em entraves, impedimentos, limites difíceis de transpor. Certamente, essa metamorfose se dará, em parte, é claro, pela nossa forma de compreender o mundo, a vida; e, também, pela timidez ou pouca ousadia em experimentar estratégias distintas e caminhos outros que poderiam enfraquecer os condicionamentos.

Um destaque importante no texto referido é a alusão que Prigogine faz à personalidade, aos valores e ao modo de viver de Albert Einstein, que se tornam verdadeiros 'obstáculos epistemológicos', (Gaston Bachelard) à aceitação da ideia de que o tempo é irreversível. Como um homem que fazia da prática científica um espaço para se proteger do 
cotidiano, para 'escapar dos impedimentos da vida, dos tormentos e desilusões de um mundo mutável e enganoso' (PRIGOGINE, 2009, p. 94) poderia aceitar o tempo como irreversível? Aceitar a irreversibilidade do tempo é compreender que o futuro está aberto, portanto é indeterminado; que o passado não é causa determinante do presente, nem do devir; que ações individuais podem alterar a dinâmica dos condicionamentos e a direção das mudanças e da história; que é crucial aceitar o desafio de agir no momento, tomar decisões, empreender ações.

Mas o sujeito Albert "era um homem muito solitário que possuía poucos amigos e poucos alunos. Chegou mesmo a afirmar que os relacionamentos com suas esposas eram difíceis. Podemos acrescentar a isso que ele presenciou o começo do antissemitismo e os pesadelos de duas guerras mundiais" (PRIGOGINE, 2009, p. 92). Para Einstein, "a ciência era uma maneira de escapar da condição humana e contemplar os esplendores da razão que agiam na natureza" (PRIGOGINE, 2009, p. 93). Nas palavras do próprio pai da teoria da relatividade, "um dos motivos mais poderosos que leva as pessoas à arte e à ciência é o desejo de sair de uma existência monótona, com seu sofrimento e vazio desesperadores, para escapar da escravidão de desejos pessoais que não param de mudar" (EINSTEIN apud PRIGOGINE, 2009, p. 92).

O sujeito Einstein se diluiu assim no corpo sem víscera de uma ciência impessoal, sem alma, sem sujeito. Seus desejos se diluíram nos músculos frios de uma razão sem desejos. Albert acabou sendo capturado por um modelo de viver e pensar que ele próprio foi gestando - em parte inconscientemente, em parte pelo artifício da racionalização. Esse estilo de pensar e viver não poderia alimentar-se da metamorfose, própria da noção de irreversibilidade do tempo. Não poderia incluir também a escolha, a persistência e a obstinação em mudar o mundo.

Não é somente Ilya Prigogine quem problematiza a simbiose entre a vida do cientista e as teorias que ele aceita ou constrói. Os físicos David Bohm e David Peat, em Ciência, ordem $e$ criatividade, falam de uma 'infraestrutura tácita de ideias e conceitos' que subjaz às formulações tidas como as mais exatas para descrever os fenômenos. Valores pessoais, princípios, crenças e circunstâncias psicológicas modulam, em escalas variadas, as interpretações que construímos, assinalam os dois autores. Mas, mesmo que o conjunto dos axiomas e argumentos do livro se dirijam a discutir como ultrapassar os obstáculos da infraestrutura tácita, não é possível imaginar a situação ideal de um sujeito que se 
desvencilhe, por completo, dos seus padrões cognoscentes habituais, que incluem suas crenças e visões de mundo.

Assim, os antigos valores e modos de conhecer se constituem em tranquilizantes para o sujeito que acaba por fazer associações equivocadas e não as percebe como equivocadas. De qualquer forma, ainda que consideremos a necessidade de 'pôr em suspensão nossas crenças e visões de mundo', como propõem Bohm e Peat, é sempre a partir de um padrão psíquico-subjetivo que compreendemos o mundo à nossa volta. Daí porque é importante narrarmos nossos percursos de autoformação, incluindo a vivência no ambiente familiar, as experiências em situação de aprendizagem extraescolar, as relações de amizade, os laços de afetos e desafetos, as situações traumáticas, as violências sofridas, os obstáculos impostos por diversas esferas do mundo social. Se nenhuma experiência vivida pode ser transferida, ela pode ser, sim, compartilhada. E, se compartilhada, pode permitir a emergência dos processos mentais de identificação e projeção, essências na vida em comum, em grupo.

Experiências de vida, saberes acumulados, desafios enfrentados, história pessoal são, pois, a base inarredável sobre a qual se constroem as interpretações e as teorias nas ciências. As palavras de Erwin Schrödinger, físico austríaco e Nobel de Física de 1933, fazem todo sentido aqui. 'Tudo que sabemos, sabemos por nossa própria experiência', diz ele. O relato de sua trajetória intelectual no texto Fragmentos Autobiográficos escrito em 1960, mostra bem como seu interesse pela biologia e pela física emerge do rico contexto de experiências diversas, que incluia o ambiente familiar, os amigos, as viagens, o clima cruel da guerra de 1914, as leituras.

No conjunto das "Conferências de Tamer", que tem por título Mente e matéria, Schrödinger problematiza o princípio da objetividade. Para ele, por meio desse princípio "excluímos o sujeito cognoscente do domínio da natureza que nos esforçamos para entender. Retrocedemos para o papel de um espectador que não pertence ao mundo, o qual, por esse mesmo procedimento torna-se um mundo objetivo" (SCHRÖDINGER, 1977, p. 132). O princípio da objetivação na ciência só se sustenta se o sujeito se concebe separado da natureza, fora do mundo, desconectado do objeto que constrói, estuda. Suas palavras a esse respeito são exemplares: "meu próprio corpo (ao qual minha atividade mental está tão direta e intimamente vinculada) forma parte do objeto (o mundo em torno de mim) que construo a partir de minhas sensações, percepções e memórias" (Idem, ibidem). Mesmo que se trate de meta-argumentos atinentes a uma epistemologia geral, as reflexões desse físico prefiguram, já 
nos anos 50 do século passado, uma crítica contundente à separação entre o sujeito que conhece e o objeto do qual se ocupa.

Por sua vez, Werner Heisenberg, no livro A parte e o todo (1986), expõe a dinâmica eminentemente coloquial, afetual e simultaneamente tensa que tece o contexto da fabricação da ciência. Uma ciência tecida por sujeitos de carne e osso poderia muito bem aparecer como subtítulo do livro. No prefácio, uma advertência essencial: "É evidente, mas muito frequentemente esquecido, que a ciência é feita por homens (...). Este livro versa sobre o desenvolvimento da física atômica nos últimos cinquenta anos, tal como o autor os vivenciou" (Op. cit. p.7). Ao longo das 286 páginas da edição brasileira, Heisenberg reconstrói os cenários diversos no interior dos quais foram sendo elaborados importantes conceitos da física e da mecânica quânticas: complementaridade, simultaneidade, probabilidade, incerteza, entre outros.

As longas conversas entre Niels Bohr, Carl Friedrich, Otto Hahn, Paul Dirac e outros cientistas, deixam entrever os cenários afetivos que estão na base da construção da ciência. Uma intersubjetividade explícita pode ser depreendida da leitura desse livro. Uma crítica aguçada ao que se considera, na ciência positivista, como objetivo e subjetivo aparece em vários momentos da reconstituição narrativa da nova física, em A parte e o todo. Para Bohr, “são realmente problemáticos os conceitos de 'objetivo' e 'subjetivo', que normalmente usamos com tanto desembaraço" (BOHR apud HEISENBERG, op. cit. p. 126). Isso porque a interpretação da realidade é empreendida por sujeitos com valores e concepções de mundo que vão se consolidando por meio de suas experiências. Daí porque, conforme relata Heisenberg, era muito difícil para Einstein aceitar a nova teoria quântica, mesmo que Bohr tenha demonstrado para ele a persistência do princípio da incerteza. Esse fato levará Heisenberg a afirmar:

compreendi como é difícil alguém abrir mão de uma atitude em que se baseava toda a sua abordagem e toda a sua carreira científica. Einstein dedicara a vida a investigar o mundo objetivo de processos físicos que têm lugar no espaço e no tempo, independentes de nós, de acordo com leis exatas. (HEISENBERG, 1996, p. 98).

É sem dúvida Edgar Morin o pensador contemporâneo que expõe com mais radicalidade e pertinência o exercício de um sujeito implicado no conhecimento. Seja em escritos considerados autobiográficos como Meus Demônios, Meu Caminho, e outros; nos seus diários (Um ano sísifo; Amar, chorar, rir e compreender; $X$ da questão: o sujeito à flor da pele, Diário da Califórnia e outros), ou na magnitude de sua obra seminal O Método, 
desdobrada em seis tomos, esse artesão do pensamento complexo expõe, muitas vezes sem mediação, sua interioridade, seus desencantos, sua vida amorosa, seus insights, suas indeterminações. Dirá ele, em Meus Demônios, "não sou daqueles que têm uma profissão, mas daqueles que têm uma vida".

Edgar, que não se esconde nas palavras, mas que se expõe perigosamente por meio delas, dirá no livro Meus Demônios que a autoética

exige-me que não dissimule a subjetividade nos meus escritos, que não me arvore em proprietário da verdade objetiva, que deixe que o leitor me veja, incluindo as fraquezas e mesquinharias, mesmo correndo o risco de dar aos meus adversários motivos para me ridicularizarem. (MORIN, 1997, p.74).

Seja qual for o tom ou a coloração das iras e afetos que aparecem em sua obra, é o sujeito encarnado nas ideias quem fala sempre. E por inteiro. No Método I (1979, p. 26) dirá quase no final da Introdução:

\footnotetext{
Por que falar de mim? Não é decente, normal e sério que, quando se trata da ciência, do conhecimento e do pensamento, o autor se apague atrás de sua obra e se desvaneça num discurso tornado impessoal? Devemos, pelo contrário, saber que é aí que a comédia triunfa. O sujeito que desaparece no seu discurso instala-se, de fato, na torre de controle. Fingindo deixar um lugar ao sol copernicano, reconstitui um sistema de Ptolomeu cujo centro é o seu espírito.
}

Desafiantes, essas considerações ganham densidade epistemológica quando o autor trata da construção psicocognitiva do sujeito do conhecimento. No Método III, Edgar dedicase à 'Existencialidade do conhecimento' por meio de dois tópicos: 'A psique' e 'Obsessões cognitivas e alegrias da certeza'. Dialoga com referências da psicanálise, sobretudo com as ideias de Freud, Lacan e Bishot; problematiza os conceitos de objetividade, certeza e verdade tão defendidos pelo racionalismo. Discute uma psicanálise do conhecimento, fala das psicoses que "determinam visões de mundo específicas e impõem sentidos às informações, acontecimentos, situações". Seja na sua forma maníaca ou esquizofrênica, esses estados do ser parasitam e modelam interpretações marcadas ora pelo exagero racional da coerência, ora pelo exagero das contradições e incertezas. De forma contundente, Edgar Morin mostra como a obsessão pela certeza e pela verdade são respostas à ansiedade vital do homem.

Ilya Prigogine, Erwin Schrödinger, Werner Heisenberg, Edgar Morin. Sujeitos inteiros. Construtores de uma ciência encarnada. Será que foi essa a perspectiva que nos foi dada a conhecer em nossa formação? Provavelmente, não. Certamente, é uma história da 
ciência pela metade, ou amputada de sua dinâmica vital, social e humana que chega às salas de aula em todos os níveis. Nas universidades e nas disciplinas dedicadas à pesquisa essa ausência do sujeito do conhecimento se torna mais explícita. Assim, se libertar dos aspectos subjetivos; produzir análises que se restrinjam a enunciar os fenômenos como eles supostamente são; e construir interpretações desprovidas dos valores e visões de mundo do observador são alguns dos princípios referendados pelos ideários de uma ciência da assepsia, destituída de sujeito, purificada dos afetos, iras, marcas inconscientes, ideologias e valores éticos dos quais se nutrem - queiramos ou não - estudantes, professores e pesquisadores de todas as áreas do conhecimento e de todos os tempos e lugares.

Avançando nessa direção, é importante assinalar que a defesa da objetividade, da neutralidade do pesquisador e de um saber destituído das marcas do autor-sujeito fazem parte do paradigma da redução, da simplificação, da fragmentação que foi, e lamentavelmente ainda é (por falta de informação ou leitura superficial e distorcida da história da ciência) repetidamente disseminado nas escolas e universidades.

Ora, uma incursão mais cuidadosa na produção da ciência permite identificar dezenas de publicações que explicitam a imbricação do ser do autor nas palavras, argumentos e textos que materializam a produção científica. Ainda que sejam classificadas como textos romanciados, ensaísticos e $\underline{a d} \underline{h o c}$, e sejam publicados separados da obra pela qual os cientistas foram consagrados, são exemplares os livros ou coletâneas que exibem a face um pouco mais completa de Galileu Galilei, Albert Einstein, Gutenberg, Karl Marx, Werner Heisenberg, Martin Heidegger, entre outros. Essas publicações são, às vezes, desclassificadas como 'obras de divulgação', o que demonstra o quanto o paradigma da racionalização se defende da contaminação do sujeito. Vivas e pulsantes, entretanto, elas descortinam contextos, eventos, obstinações e circunstâncias afetivas que servem de magma para uma "ciência feita por homens". Importantes, tais narrativas expõem o lado vivo de uma ciência levada a efeito por pessoas de carne e osso e alimentadas por suas euforias, pessimismos, obsessões, sonhos, utopias, traumas, emoções.

Em síntese, os argumentos, circunstâncias e reflexões até aqui expostos e, sobretudo, as referências feitas a Edgar Morin, permitem destacar uma das formulações fundamentais do pensamento complexo, isto é, a implicação do sujeito no conhecimento. Dessa proposição poder-se-ia inferir, por consequência, a implicação do autor na narrativa. Trata-se, pois, de: a) tomar consciência dessa implicação; b) relativizar o sentido da objetividade pretendido pela ciência; c) reduzir o sentimento da verdade absoluta; e d) ampliar 
os diálogos intersubjetivos entre pesquisadores, de modo a consolidar uma ecologia das ideias. Essa agenda, mesmo que incompleta e provisória, poderia ajudar a desfazer o equívoco de uma ciência abstrata, impessoal, sem paixão, neutra, objetiva, sem sujeito.

\section{REFERÊNCIAS BIBLIOGRÁFICAS}

AGAMBEN, Giorgio. O que é o contemporâneo? E outros ensaios. Chapecó: Argos, 2009.

ATLAN, Henri. O livro do conhecimento. As centelhas do acaso. Tomo I-Conhecimento espermático. Tradução Maria Ludovina Fiqueredo. Lisboa: Instituto Piaget, 2000.

BAITELLO JUNIOR, Norval. O pensamento sentado: sobre glúteos, cadeiras e imagens. São Leopoldo/RS: Ed. Unisinos, 2012

A serpente, a maçã e o holograma. Esboço para uma Teoria da Mídia. São Paulo: Paulus, 2010

BIRMAN, Joel. O sujeito na contemporaneidade. Rio de Janeiro: Civilização Brasileira, 2012. BRETON, André. Manifestos do Surrealismo. Tradução Pedro Tamen. Lisboa: 1993

BOHM, David. Ciência, ordem e criatividade. Lisboa: Gradiva, 1989.

DELEUZE, Gilles. Conversações. Rio de Janeiro: Ed. 34, 1992

; GUATTARI, Félix. O que é a filosofia? Tradução Bento Prado Jr. e Alberto Alonso Munoz. Rio de Janeiro: Ed. 34, 1992

HEISENBERG, Werner. A parte e o todo. Rio de Janeiro: Contraponto, 1996.

LÉVI-TRAUSS, Claude. Tristes trópicos. Tradução Rosa Freire d'Aguiar. São Paulo: Companhia das Letras, 1996

O homem nu (Mitológicas v. 4). Tradução Beatriz Perrone-Moisés. São Paulo: Companhia das Letras, 2011

LÉVI-STRAUSS, Claude. Entrevista a Boris Wiseman. O remorso da ficção. Jornal Folha de São Paulo. Caderno Mais! São Paulo, 22 de maio de 2005, p. 6

LATOUR, Bruno. Ciência em ação. Como seguir cientistas e engenheiros sociedade afora.

Tradução Ivone C. Beneditti. São Paulo: Ed. UNESP, 2000

MORIN, Edgar. Diário da Califórnia. Madri: Editorial Fundamentos, 1973. 
NICOLESCU, Basarab. La Trasdisciplinariedad - Manifesto. Jean-Paul Bertrand (Editor): Mexico. Multiversidad Mundo Real Edgar Morin, 1996

PRIGOGINE, Ilya. Ciência, razão e paixão (Org. Edgard Assis de Carvalho e Maria da Conceição Xavier de Almeida). Belém: EDUEPA, 2001. . Do ser e do devir. Entrevistas a Edmond Blattchen. São Paulo: UNESP/EDUEPA, 2002 (Coleção Nomes de Deuses). . O reencantamento da natureza. In: WEBER, Renée. Diálogos com cientistas e sábios: a busca da unidade. Tradução Gilson Cesar C. de Souza. São Paulo: Cultrix, 1986.

REEVES, Hubert. Os artesãos do oitavo dia. Entrevistas a Edmond Blattchen. Tradução de Maria Leonor F. R. Loureiro. São Paulo: Unesp;Belem: Editora da Universidade do Estado do Pará, 2002 (Coleção Nome de Deuses)

ROSNAY, Jöel. O macroscópio - Para uma visão global. Lisboa: Estratégia Criativa, 1995

SERRES, Michel. Variações sobre o corpo. Tradução Edgard de Assis Carvalho e Mariza Perassi Bosco. Rio de Janeiro: Bertrand Brasil,2004

STENGERS, Isabelle. A invenção das ciências modernas. São Paulo: Ed. 34, 2002.

VERGANI, Teresa. A Palavra e a pedra. Lisboa: Universidade Aberta e Teresa Vergani, 1993. 